\title{
General Psychiatry Cross-sectional study of internalised stigma and medication adherence in patients with obsessive compulsive disorder
}

\author{
Eram Ansari, ${ }^{1}$ Sudha Mishra, ${ }^{1}$ Adarsh Tripathi, ${ }^{2}$ Sujita Kumar Kar (D) , ${ }^{2}$ \\ Pronob Kumar Dalal ${ }^{2}$
}

To cite: Ansari E, Mishra S, Tripathi A, et al. Cross-sectional study of internalised stigma and medication adherence in patients with obsessive compulsive disorder. General Psychiatry 2020;33:e100180. doi:10.1136/ gpsych-2019-100180

Received 03 November 2019 Revised 17 December 2019 Accepted 06 February 2020

\section{Check for updates}

(c) Author(s) (or their employer(s)) 2020. Re-use permitted under CC BY-NC. No commercial re-use. See rights and permissions. Published by BMJ.

${ }^{1}$ College of Nursing, King George's Medical University, Lucknow, India

${ }^{2}$ Department of Psychiatry, King George's Medical University, Lucknow, India

Correspondence to Dr Sujita Kumar Kar; drsujita@gmail.com

\section{ABSTRACT}

Background Patients suffering from psychiatric disorders tend to stigmatise themselves which had been linked to poor adherence to treatment.

Aims The aim of the present study was to study internalised stigma and medication adherence and to assess the relationship between them in patients with obsessive compulsive disorder (OCD).

Methods A cross-sectional study was conducted on 112 patients diagnosed with OCD who were attending the Out-patient's department at Department of Psychiatry of a tertiary care hospital in North India. Internalised stigma and current medication adherence were assessed with Internalized Stigma of Mental IIIness Scale (ISMI) and Medication Adherence Rating Scale, respectively. YaleBrown Obsessive Compulsive Scale was used to assess the current severity of OCD symptoms. Sociodemographic and clinical details were also obtained from the patients by using a semistructured sociodemographic proforma.

Results Most of the patients reported moderate level of internalised stigma with a mean ISMI score of 77.98 (10.82). Most of the patients were compliant while $41.96 \%$ reported poor medication adherence. Internalised stigma was negatively correlated with the current medication adherence. Current severity of OCD symptoms also showed a significant positive correlation with internalised stigma and a significant negative correlation with medication adherence.

Conclusion High levels of internalised stigma were associated with lower adherence to treatment which suggests that internalised stigma may be a very important factor influencing medication adherence in patients with OCD.

\section{INTRODUCTION}

Psychiatric patients are often victims of prejudices and biases (stigma), globally. ${ }^{1}$ Stigma often adversely affects the treatment of such individuals. $^{2}$ Many individuals with mental health problems also suffer from self-stigma. ${ }^{3}$ Self-stigma or internalised stigma is a gradual process in which a person uncritically adopts negative societal prejudices about attributes that are discredited by others. ${ }^{2}$ Self-stigma also negatively influences the psychological well-being of the patients, as well as treatment efficiency. ${ }^{3}$ Literature supports that $64.5 \%$ of patients with schizophrenia perceived stigma and alienation were found to be the most common aspects of internalised stigma with $49.2 \%$ of reporting. ${ }^{4}$ A nationwide study from India revealed that patients with severe mental disorders experience high levels of self-stigma. ${ }^{5}$

Non-adherence is still a global challenge in the field of psychiatry. ${ }^{6}$ Literature review showed that $41.2 \%-49.5 \%$ of patients with schizophrenia were non-adherent to the treatment. Medication non-adherence for unipolar and bipolar depressive disorders ranges from $10 \%$ to $60 \% .^{7}$ Individuals suffering from mental illnesses may have serious consequences of non-adherence. Literature supports that non-adherence is strongly linked to relapse, rehospitalisation and suicide rates. ${ }^{8}$

Obsessive compulsive disorder (OCD) is the fourth most common mental disorder. ${ }^{9}$ In Indian setting, a study found that the lifetime prevalence of OCD was $0.6 \% .{ }^{10}$ In Uttar Pradesh, which is the most populous state of India, the prevalence of OCD was $0.51 \% .^{11}$

Individuals having psychiatric illness suffer from both social stigma and self-stigma. ${ }^{3}$ Patients suffering from OCD are no exception. Fear of stigmatisation is the reason why people suffering from OCD avoid seeking adequate help which further deteriorates their condition. Literature supports that relatives of patients with OCD anticipate or concretely experience stigma and they use concealing as a coping strategy. ${ }^{12} 13$ Another study has identified stigma, internal or cognitive factors, lack of knowledge regarding their illness and fear of criminalisation as barriers to seek help in patients with OCD. ${ }^{14}$ 
Belloch et al found that fear of stigma and the meaning of thought contents were the main barriers to help seeking in patients with OCD. ${ }^{15}$ A study showed that $80 \%$ of the patients with OCD feared that they would be rejected at work because of their illness. ${ }^{12}$

Like in other psychiatric disorders, medication nonadherence is a major problem in patients with OCD. Santana et alfound that $46 \%$ of patients with OCD refused to undertake Cognitive Behaviour Therapy while 52\% refused to take medication and $61 \%$ had taken medication less frequently or at a smaller dose than prescribed. ${ }^{16}$ Stigma and medication adherence in patients with OCD was not so extensively studied like severe mental illnesses such as schizophrenia and bipolar affective disorder. However, patients with OCD often have a disabling life and there is a need of long-term treatment. Patients with OCD also require antiobsessive medications in relatively higher dose for longer time, which is a costly affair, which might be responsible for medication non-adherence in low and middle-income countries and underdeveloped countries. Internalised stigma may also negatively influence medication adherence in such patients.

So, the present study was aimed to study internalised stigma and medication adherence and also to assess the relationship, if any, between internalised stigma and medication adherence in patients with OCD.

\section{MATERIALS AND METHODS}

A cross-sectional study was conducted from November 2018 to February 2019 at the Department of Psychiatry of a tertiary care teaching hospital in North India. Purposive sampling technique was employed to draw the sample. Patients willing to participate in the study, with age group of 18-60 years, diagnosed with OCD according to International Classification of Diseases 10th Revision (ICD10 ) and who were on medication for OCD (must be on prescribed medication by a qualified psychiatrist in the past for $\geq 3$ months), were included in the study. Patients with any severe medical comorbidity and those having other psychiatric comorbidities except tobacco use and depressive disorder were excluded.

\section{Assessment instruments}

1. Semistructured sociodemographic proforma

It was developed by the researcher, which contains information about patient's age group, gender, domicile, education, marital status, occupation, monthly family income, age of onset of illness, duration of illness, duration of treatment, mode of treatment, any medical comorbidity, any psychiatric comorbidity, family history of any psychiatric illness and current treatment details.

2. Mini-International Neuropsychiatric Interview version 7.0 .2

It is a brief structured interview for the major psychiatric disorders in Diagnostic and Statistical Manual of Mental Disorders, Fifth Edition, and ICD-10 developed by David Sheehan ${ }^{17}$ and was used to screen and rule out any other psychiatric comorbidity in the study subjects.

3. Yale-Brown Obsessive Compulsive Scale (Y-BOCS)

This is a widely used standard clinician-rated interview scale designed to assess the severity of OCD symptoms. It has 10 items and each item is rated from 0 (no symptom) to 4 (extreme symptoms), giving a total score ranging from 0 to $40{ }^{18}$

4. Internalized Stigma of Mental Illness Scale (ISMI)

It is a 29-item measure with five subscales (alienation, stereotype endorsement, discrimination experience, social withdrawal and stigma resistance) on a 4-point Likert scale (1 to 4) for assessing the internalised stigma of patients towards the mental illness, originally developed by Jennifer Boyd Ritsher. ${ }^{19}$ In this study, a Hindi version of ISMI was used which is developed by Singh et $_{\text {al. }}{ }^{20}$

5. Medication Adherence Rating Scale (MARS)

It is a self-report measure of medication adherence in psychiatric patients, developed by Thompson. ${ }^{21}$ It has $10 \mathrm{yes} /$ no items and the sum of items yields a final score ranking from 0 to 10. A total score reflects a greater degree of adherence, if it is high, and nonadherence, if it is low. ${ }^{21}$ A total score of $\leq 5$ is considered as non-adherence, while that of $\geq 6$ is considered as adherence to medications, in this study.

The primary investigator had done all assessments in order to avoid assessment biases. Validated tools were used. Sample size was calculated as 112 , so screening of the patients was done until the desired sample size has reached.

\section{Data analysis}

Statistical analysis was done by using Statistical Package for the Social Sciences (SPSS V.16.0). Descriptive statistics was used to calculate the mean, SD, range and frequency of sociodemographic and clinical variables, severity of symptoms of OCD, internalised stigma and medication adherence. Spearman's correlation was used to assess the relationship between internalised stigma and medication adherence. Kruskal-Wallis test and Mann-Whitney test were used to find out the association of internalised stigma and medication adherence with sociodemographic and clinical variables. $P$ value $<0.05$ was considered significant.

\section{RESULTS}

\section{Sample characteristics}

A total of 155 patients were screened out of which 112 were included in the study (figure 1). Most of the patients were in the age group of $18-30$ years $(52.67 \%)$ with a mean age of 32.04 (9.41) years. Most of the patients were female $(58.92 \%)$, belonged to rural areas $(55.36 \%)$ and were married $(66.07 \%)$. $44.64 \%$ of the patients were housewives. Most of the participants were graduates $(33.03 \%)$ and had monthly family income of 10000-20 000 rupees $(44.64 \%)$. Most of the patients had more 


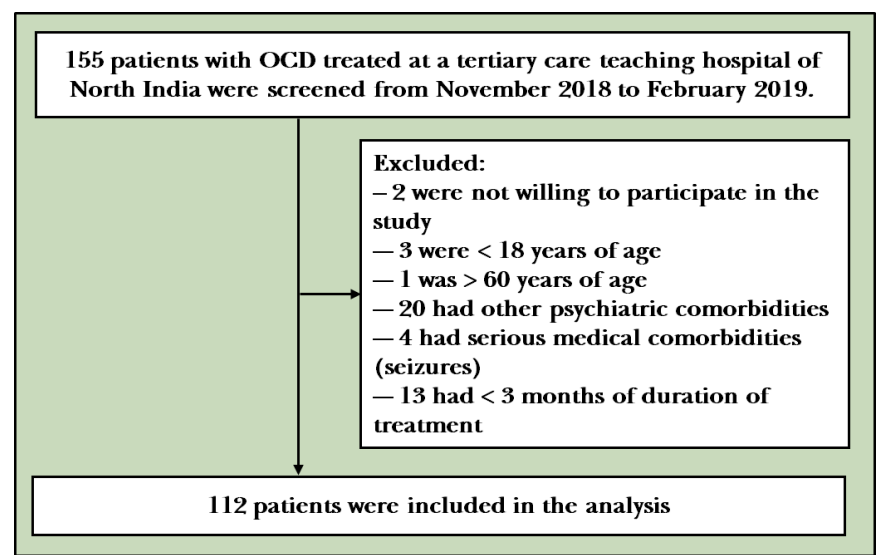

Figure 1 Flow chart for enrolment of subjects. OCD, obsessive compulsive disorder.

\begin{tabular}{lll}
\hline $\begin{array}{l}\text { Table 1 } \\
(\mathrm{n}=112)\end{array}$ & Sociodemographic profile of patients & with OCD \\
\hline $\begin{array}{l}\text { Sociodemographic } \\
\text { variables }\end{array}$ & Categories & $\begin{array}{l}\text { Frequency } \\
\text { (\%) }\end{array}$ \\
\hline Age group (years) & $18-30$ & $59(52.67)$ \\
& $31-40$ & $24(21.42)$ \\
& $41-50$ & $28(25)$ \\
& $51-60$ & $1(0.89)$ \\
\hline Gender & Male & $46(41.07)$ \\
& Female & $66(58.92)$ \\
\hline Domicile & Rural & $62(55.36)$ \\
& Urban & $50(44.64)$ \\
& Illiterate & $8(7.14)$ \\
& Up to 5th & $11(9.82)$ \\
& 6th-8th & $10(8.92)$ \\
& Up to 10th & $13(11.6)$ \\
& Up to 12th & $21(18.75)$ \\
\hline Gducation & Graduate & $37(33.03)$ \\
& Postgraduate and & $12(10.71)$ \\
& others & \\
\hline Marital status & Married & $74(66.07)$ \\
& Unmarried & $35(31.25)$ \\
& Divorced/separated & $1(0.89)$ \\
& Widow/widower & $2(1.78)$ \\
\hline (rupees) & Student & $22(19.64)$ \\
& Unemployed & $7(6.25)$ \\
& Government job & $7(6.25)$ \\
& Private job & $26(23.21)$ \\
& Housewife & $50(44.64)$ \\
\hline Uccupation & Up to 10000 & $25(22.32)$ \\
& $>20000-20$ 000 & $50(44.64)$ \\
& $37(33.03)$ \\
\hline & & \\
& & \\
& &
\end{tabular}

OCD, obsessive compulsive disorder.
Table 2 Clinical profile of patients with OCD $(n=112)$

\begin{tabular}{|c|c|c|}
\hline Variables & Mean (SD) & Range (years) \\
\hline $\begin{array}{l}\text { Age of onset of illness } \\
\text { (years) }\end{array}$ & $25.75(8.553)$ & $11-44$ \\
\hline Duration of illness (years) & $6.30(5.519)$ & $0.5-25$ \\
\hline $\begin{array}{l}\text { Duration of treatment } \\
\text { (years) }\end{array}$ & $2.79(3.173)$ & $0.25-14$ \\
\hline
\end{tabular}

OCD, obsessive compulsive disorder.

than 2 years of duration of illness $(72.32 \%)$, and had taken more than 1 year of treatment $(52.67 \%)$ (table 1$)$. Majority of the participants were on psychopharmacological treatment alone (96.42\%), had no comorbid medical illness $(96.64 \%)$, no family history of any psychiatric illness $(84.82 \%)$ and most had no current comorbid psychiatric illness $(66.07 \%)$. Depression (current) was the most common psychiatric comorbidity $(23.21 \%)$ in the patients and $8.03 \%$ of the patients had a family history of OCD, followed by that of depression $(4.46 \%) .51 .78 \%$ of the patients were being treated with Selective Serotonin Reuptake Inhibitors (SSRIs) alone, while augmenting agents were used along with SSRIs and/or Tricyclic Antidepressants (TCAs) in $36.60 \%$ of the patients. Along with the antidepressants, antianxiety agents were also used in $74.10 \%$ of the patients. Table 2 shows the clinical profile of the patients.

Of all the patients, $31.25 \%$ were rated as severe and $29.46 \%$ as moderate on Y-BOCS, followed by mild in $26.78 \%$. Most of the patients had moderate level of internalised stigma $(49.1 \%)$, followed by mild internalised stigma in $29.46 \% .19 .64 \%$ had severe stigma while only $1.78 \%$ had reported minimal to no internalised stigma, as rated by ISMI. Most of the patients were compliant $(58.03 \%)$ and the remaining $(41.96 \%)$ were non-compliant. Table 3 shows the mean scores of Y-BOCS, ISMI and MARS along with the mean scores on domains of ISMI. Higher scores (except in stigma resistance domain) indicate higher internalised stigma. Alienation domain had a higher mean score (18.71(3.09)) than other domains.

The severity of OCD symptoms had a significant positive correlation with internalised stigma, as rated by ISMI (with all the domains as well as the overall ISMI scores). A significant negative correlation was found between internalised stigma (all the domains as well as an overall ISMI score) and medication adherence (table 4). In other words, the higher the internalised stigma in the patients, the lower was their current medication adherence and the more severe their diseased condition. Figure 2 also depicts the relationship between internalised stigma and medication adherence. A significant negative correlation $(\mathrm{r}=-0.425, \mathrm{p}<0.001)$ was also found between severity of OCD symptoms and medication adherence.

In gender, pairwise comparison showed a significant difference with internalised stigma $\left(\chi^{2}=2.165, \mathrm{p}=0.020\right)$. In domicile, pairwise comparison showed a significant 
Table 3 Score profile of Y-BOCS, ISMI and MARS in patients with OCD $(n=112)$

\begin{tabular}{llc}
\hline & Mean (SD) & Score range \\
\hline Y-BOCS & $20.37(8.309)$ & $0-35$ \\
\hline ISMI & $77.98(10.816)$ & $52-108$ \\
$\quad$ Alienation & $18.71(3.086)$ & $12-24$ \\
\multicolumn{1}{c}{ Stereotype endorsement } & $16.33(3.003)$ & $10-25$ \\
Discrimination experience & $12.59(2.163)$ & $8-18$ \\
Social withdrawal & $16.78(2.786)$ & $11-22$ \\
\multicolumn{1}{c}{ Stigma resistance } & $13.59(2.622)$ & $5-20$ \\
MARS & $6.63(2.360)$ & $2-10$ \\
\hline
\end{tabular}

ISMI, Internalized Stigma of Mental IIIness Scale; MARS, Medication Adherence Rating Scale; OCD, obsessive compulsive disorder; Y-BOCS, Yale-Brown Obsessive Compulsive Scale.

difference with current severity of OCD (Mann-Whitney, sig $=0.041$ ) and internalised stigma (Mann-Whitney, sig $=0.016$ ). In education, pairwise comparison showed a significant difference with current severity of OCD $\left(\chi^{2}=12.918, \quad \mathrm{p}=0.044\right)$ and medication adherence $\left(\chi^{2}=13.999, \mathrm{p}=0.030\right)$. Pairwise comparison showed a significant difference between marital status and medication adherence $\left(\chi^{2}=8.891, \mathrm{p}=0.031\right)$. In occupation, pairwise comparison showed a significant difference with current severity of OCD $\left(\chi^{2}=12.288, p=0.015\right)$ and internalised stigma $\left(\chi^{2}=14.017, \mathrm{p}=0.007\right)$. No significant difference was observed in age group (table 5 ).

Duration of illness had a significant $(r=-0.201, p=0.033)$ negative correlation with severity of symptoms of OCD. Duration of treatment also had a significant $(r=-0.377$ $\mathrm{p}<0.001)$ negative relationship with severity of symptoms of OCD, while age of onset of illness, duration of illness and duration of treatment were found to have no significant relationship with internalised stigma and medication adherence.

\section{DISCUSSION}

\section{Main findings}

In the present study, the mean age of the patients was found to be 32.04 (9.41) years, and most patients were female and married, which is similar to other studies conducted in this geographical region. ${ }^{22} 23$ The mean age of onset of illness was 25.75 (8.55) years, as seen in other studies. ${ }^{22} 24$ Among the psychiatric comorbidities, depression was found to be the most common (23.21\%), a finding that is consistent with other studies. ${ }^{24}{ }^{25} \mathrm{~A}$ retrospective study on 451 cases of OCD in children and adolescents by Deepthi et al found that $17.1 \%$ of the participants had a family history of OCD in first-degree relative,${ }^{25}$ while $8.03 \%$ of our subjects had a family history of OCD. This variation may be due to comparatively smaller sample size and stringent selection criteria in our study. An Indian study reported a mean Y-BOCS score of 25.86 (8.07), which was similar to that of our study. ${ }^{22}$

Most of the patients in our study reported moderate level of internalised stigma with a mean ISMI score of 77.98 (10.82). A mean ISMI score of 69.09 (14.47) was found in patients with OCD in one study. ${ }^{26}$ Another study on patients with mixed neurotic spectrum and depressive disorders revealed a mean ISMI score of 66.78 (13.71). ${ }^{27}$ Other studies also showed similar results. ${ }^{2228}$ This underlines that self-stigma is a matter of concern for those suffering from severe mental illnesses and to those with OCD. Our study findings showed that the subscale alienation had a higher mean score than other domains with the lowest mean score in stigma resistance domain. The findings vary across different studies. A study by Ociskova et al found a higher score in alienation (15.58 (4.33)), a finding similar to our study, ${ }^{27}$ while another study showed higher scores in stigma resistance domain. ${ }^{28}$ Hajda et al have found higher scores in subscales of stereotype endorsement as well as stigma resistance. ${ }^{29}$ This difference in subscale scores may be attributed to cultural variations and the way a society treats patients with mental illness.

Santana et al found that $61 \%$ of the patients with OCD had taken their medication less frequently or at lesser

Table 4 Correlation (Spearman's correlation, $r$ ) of severity of OCD (as per Y-BOCS) and medication adherence (as per MARS) with domains of Internalized Stigma of Mental IIIness Scale (ISMI) in patients with OCD ( $n=112)$

\begin{tabular}{llllllc}
\hline & Alienation & $\begin{array}{l}\text { Stereotype } \\
\text { endorsement }\end{array}$ & $\begin{array}{l}\text { Discrimination } \\
\text { experience }\end{array}$ & $\begin{array}{l}\text { Social } \\
\text { withdrawal }\end{array}$ & $\begin{array}{l}\text { Stigma } \\
\text { resistance }\end{array}$ & $\begin{array}{c}\text { ISMI } \\
\text { total }\end{array}$ \\
\hline $\begin{array}{l}\text { Y-BOCS } \\
\text { Spearman's correlation, } r\end{array}$ & $0.545^{\star}$ & $0.473^{*}$ & $0.308^{*}$ & $0.447^{*}$ & $0.626^{*}$ & $0.609^{*}$ \\
\hline P value & $<0.001$ & $<0.001$ & 0.001 & $<0.001$ & $<0.001$ & $<0.001$ \\
MARS & & & & & \\
$\quad$ Spearman's correlation, $r$ & $-0.308^{*}$ & $-0.513^{*}$ & $-0.246^{*}$ & $-0.264^{*}$ & $-0.193 \dagger$ & $-0.390^{*}$ \\
\hline P value & 0.001 & $<0.001$ & 0.009 & 0.005 & 0.041 & $<0.001$ \\
\hline
\end{tabular}

${ }^{*}$ Correlation is significant at the 0.01 significance level.

†Correlation is significant at the 0.05 significance level.

ISMI, Internalized Stigma of Mental IIIness Scale; MARS, Medication Adherence Rating Scale; OCD, obsessive compulsive disorder; Y-BOCS, Yale-Brown Obsessive Compulsive Scale. 


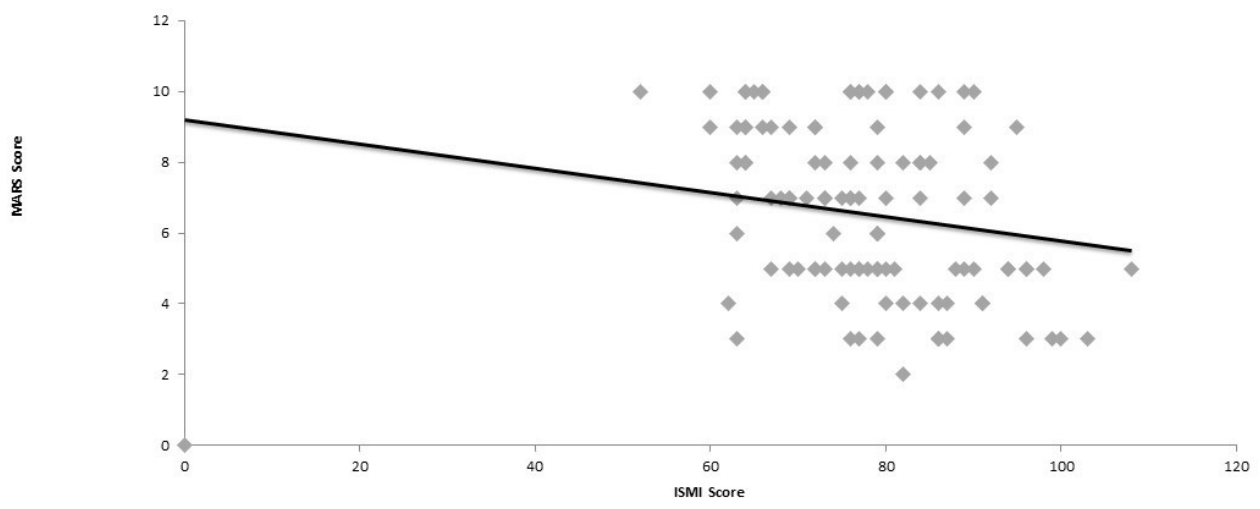

Figure. 2: Correlation between internalized stigma \& medication adherence

Abbreviations: ISMI- Internalized Stigma of Mental IIIness; MARS- Medication Adherence Rating Scale

Figure 2 Correlation between internalised stigma and medication adherence. ISMI, Internalized Stigma of Mental IIIness Scale; MARS, Medication Adherence Rating Scale.

than the prescribed doses or discontinued the medication. ${ }^{16}$ Another study reported that $48 \%$ of the psychiatric outpatients had poor adherence. ${ }^{30}$ Our findings also suggest that a considerable proportion of patients were non-adherent.

The most important finding of the present study is that the internalised stigma had a significant negative correlation with the current medication adherence, which confirms our research hypothesis. This finding is consistent with several other studies. ${ }^{26-28} 31$ So, it could be said that internalised stigma is an important factor which affects medication adherence in patients with OCD. Although its causality remained unclear from the data, it may be assumed that higher levels of self-stigma hinder the treatment seeking of patients, thus leading to non-compliance and vice versa, that is, treatment nonadherence leads to higher self-stigma. We consider the former to be more likely, as stigma and misconceptions regarding the true nature of the disorder and its treatment may act as a potential barrier in successful completion of the course of treatment. This finding also implies the importance of stigma reduction interventions.

Holubova et al reported severity of disorder as one of the most influencing factors for self-stigma. ${ }^{28}$ Our study also found a significant positive correlation between current severity of $\mathrm{OCD}$ symptoms and internalised stigma. Findings of other studies also suggest the same. ${ }^{27}$ But it remained unclear whether the severity of symptoms leads to higher levels of internalised stigma and vice versa. Our study also showed that the current severity of OCD

Table 5 Comparison of sociodemographic variables with severity of OCD (Y-BOCS), internalised stigma (ISMI) and medication adherence (MARS) in patients with OCD $(n=112)$

\begin{tabular}{|c|c|c|c|c|}
\hline Variables & Statistics (df) & Y-BOCS & ISMI & MARS \\
\hline \multirow[t]{2}{*}{ Age group } & Kruskal-Wallis test & $\chi^{2}=2.246$ & $\chi^{2}=2.165$ & $\chi^{2}=1.565$ \\
\hline & $(d f=3)$ & $P=0.523$ & $P=0.539$ & $P=0.667$ \\
\hline Gender & Mann-Whitney 'U' test & Sig $=0.067$ & Sig $=0.020^{\star}$ & Sig $=0.276$ \\
\hline Domicile & Mann-Whitney 'U' test & Sig $=0.041^{*}$ & Sig $=0.016^{\star}$ & Sig $=0.983$ \\
\hline \multirow[t]{2}{*}{ Education } & Kruskal-Wallis test & $\chi^{2}=12.918^{*}$ & $\chi^{2}=9.287$ & $\chi^{2}=13.999^{*}$ \\
\hline & $(d f=6)$ & $P=0.044$ & $P=0.158$ & $P=0.030$ \\
\hline \multirow[t]{2}{*}{ Marital status } & Kruskal-Wallis test & $\chi^{2}=5.719$ & $\chi^{2}=7.408$ & $\chi^{2}=8.891^{*}$ \\
\hline & $(d f=3)$ & $P=0.126$ & $P=0.060$ & $P=0.031$ \\
\hline \multirow[t]{2}{*}{ Occupation } & Kruskal-Wallis test & $\chi^{2}=12.288^{\star}$ & $\chi^{2}=14.017 \dagger$ & $\chi^{2}=5.386$ \\
\hline & $(\mathrm{df}=4)$ & $P=0.015$ & $P=0.007$ & $P=0.250$ \\
\hline \multirow[t]{2}{*}{ Monthly family income } & Kruskal-Wallis test & $\chi^{2}=5.934$ & $\chi^{2}=9.622^{*}$ & $\chi^{2}=4.106$ \\
\hline & $(\mathrm{df}=2)$ & $P=0.115$ & $P=0.022$ & $P=0.250$ \\
\hline
\end{tabular}

*Significant at the 0.05 significance level. †Significant at the 0.01 significance level. df, degrees of freedom; ISMI, Internalized Stigma of Mental IIIness Scale; MARS, Medication Adherence Rating Scale; OCD, obsessive compulsive disorder; Y-BOCS, Yale-Brown Obsessive Compulsive Scale. 
symptoms was significantly negatively correlated with medication adherence, possibly suggesting that medication non-compliance is linked to increased severity of disorder, although direction of causality is difficult to establish from the available data. The findings are consistent with other studies showing negative correlation between severity of disorder and medication adherence. $^{22728}$

The present study found no significant difference between age group and ISMI and MARS scores. A study on patients with anxiety disorder also found no correlation between self-stigma and age. ${ }^{31}$ Another study also supported this finding. ${ }^{2}$ However, they found a significant association in age and adherence to treatment, which was in contrast to the present study. In the present study, gender showed a significant difference with ISMI scores but not with MARS scores. Findings regarding the effect of gender on these variables are inconsistent. Kamaradova $e t$ al found no statistically significant difference in internalised stigma as well as in adherence to treatment between the sexes. ${ }^{2}$ Holubova $e t$ al reported that there is no connection between gender and self-stigma. ${ }^{28}$ These variations may arise due to different diagnostic categories being studied also in different geographical areas. Another study on patients with bipolar disorder also suggests no statistically significant difference between gender and current treatment adherence. ${ }^{29}$ Domicile showed a significant difference with ISMI scores, but no studies directly comparing domicile with any of the research variables were found, so this statement could not be confirmed. In education, pairwise comparison showed a significant difference with MARS scores. A study by Kamaradova $e t$ al found a significant difference in self-stigma and education levels. However, no significant difference was found in treatment adherence and education, which was in contrast to the findings of our study. ${ }^{2}$ This may be because these studies were carried out in different settings with different groups of patients. Marital status showed a significant difference with medication adherence in our study. Kamaradova et al found a significant difference in both self-stigma and treatment adherence with partner status, ${ }^{2}$ while a study found no significant difference between partnership statuses with medication adherence. ${ }^{29}$ These discrepancies may be attributed to cultural variations. Pairwise comparison in occupation showed a significant difference with ISMI scores, but it could not be confirmed with available studies. In our study, age of onset of illness was not significantly correlated with any of the research variables. Another study also supports this finding. ${ }^{31}$ However, age of onset was correlated with treatment adherence in a study. ${ }^{2}$ The present study also failed to find any significant correlation between duration of illness and duration of treatment with internalised stigma as well as medication adherence. There are inconsistencies in these findings across the literature, which may be attributed to varying sociocultural background and different target population.

\section{Limitations}

One of the limitations of this study was that purposive sampling technique was employed. Moreover, patients with comorbid depressive disorder were also included as this was a time-bound study and exclusion of depression from the sample would have further limited the sample size. Other limitation was that self-reported questionnaires were used to assess internalised stigma and medication adherence.

\section{Implications}

The study findings support that higher levels of selfstigma in patients with $\mathrm{OCD}$ are associated with poor medication adherence. The study results underline that attention should be paid to assess and address internalised stigma among the patients. Addressing to self-stigma may also be incorporated to the management plan of OCD. More focus should be on reducing internalised stigma and improving medication compliance through psychoeducation of patients, family members and public. Policymakers should also extensively support systematic programmes that curb stigma regarding mental illness in the society and increase social acceptance of those patients. Such interventions, targeting to minimise selfstigma, may improve adherence to treatment and thus the outcome resulting in better quality of life in these patients. Future studies should include in-depth analysis of factors contributing to self-stigma and treatment nonadherence and also try to establish causality between the two. In addition, impact of internalised stigma on treatment efficacy and outcome should also be studied.

Contributors EA is the principal investigator of the study, who collected and analysed the data, reviewed the literature and wrote the manuscript. SM and SKK helped in writing the manuscript and literature search. AT and PKD helped in editing the manuscript. All the coauthors checked the manuscript for language, analysis of data and interpretation.

Funding The authors have not declared a specific grant for this research from any funding agency in the public, commercial or not-for-profit sectors.

Competing interests None declared.

Patient consent for publication Obtained.

Ethics approval The study was approved by the Institutional Ethics Committee. Provenance and peer review Not commissioned; externally peer reviewed.

Data availability statement Data are available upon reasonable request. None.

Open access This is an open access article distributed in accordance with the Creative Commons Attribution Non Commercial (CC BY-NC 4.0) license, which permits others to distribute, remix, adapt, build upon this work non-commercially, and license their derivative works on different terms, provided the original work is properly cited, appropriate credit is given, any changes made indicated, and the use is non-commercial. See: http://creativecommons.org/licenses/by-nc/4.0/.

ORCID iD

Sujita Kumar Kar http://orcid.org/0000-0003-1107-3021

\section{REFERENCES}

1 Drapalski AL, Lucksted A, Perrin PB, et al. A model of internalized stigma and its effects on people with mental illness. Psychiatr Serv 2013;64:264-9.

2 Kamaradova D, Latalova K, Prasko J, et al. Connection between selfstigma, adherence to treatment, and discontinuation of medication. Patient Prefer Adherence 2016;10:1289-98. 
3 Ociskova M, Prasko J, Sedlackova M. Relationship between personality and Self-stigma in mixed neurotic spectrum and depressive disorders - cross sectional study. European Psychiatry 2015;30:1114-9.

4 Gerlinger G, Hauser M, De Hert M, et al. Personal stigma in schizophrenia spectrum disorders: a systematic review of prevalence rates, correlates, impact and interventions. World Psychiatry 2013;12:155-64.

5 Grover S, Avasthi A, Singh A, et al. Stigma experienced by patients with severe mental disorders: a nationwide multicentric study from India. Psychiatry Res 2017;257:550-8.

6 Chapman SCE, Horne R, Home R. Medication nonadherence and psychiatry. Curr Opin Psychiatry 2013;26:446-52.

7 Ahmed N, Gandhi S, Baruah A. Effectiveness of specific intervention on treatment adherence of persons with mental illness: a pilot study. Indian J Psychiatry 2015;57:403-6.

8 Haddad PM, Brain C, Scott J. Nonadherence with antipsychotic medication in schizophrenia: challenges and management strategies. Patient Relat Outcome Meas 2014;5:43-62.

9 Grant JE. Obsessive-Compulsive disorder. N Engl J Med Overseas Ed 2014:371:646-53.

10 Reddy YCJ, Rao NP, Khanna S. An overview of Indian research in obsessive compulsive disorder. Indian J Psychiatry 2010;52:200-9.

11 Kar SK, Sharma E, Agarwal V, et al. Prevalence and pattern of mental illnesses in Uttar Pradesh, India: findings from the National mental health survey 2015-16. Asian J Psychiatr 2018;38:45-52.

12 Ociskova M, Prasko J, Cerna M, et al. Obsessive compulsive disorder and stigmatization. Act Nerv Super Rediviva 2013;55:19-26.

13 Stengler-Wenzke K, Beck M, Holzinger A, et al. [Stigma experiences of patients with obsessive compulsive disorders]. Fortschr Neurol Psychiatr 2004;72:7-13.

14 Robinson KJ, Rose D, Salkovskis PM. Seeking help for obsessive compulsive disorder (OCD): a qualitative study of the enablers and barriers conducted by a researcher with personal experience of OCD. Psychol Psychother 2017;90:193-211.

15 Belloch A, Del Valle G, Morillo C, et al. To seek advice or not to seek advice about the problem: the help-seeking dilemma for obsessive-compulsive disorder. Soc Psychiatry Psychiatr Epidemiol 2009;44:257-64.

16 Santana L, Fontenelle JM, Yücel M, et al. Rates and correlates of nonadherence to treatment in obsessive-compulsive disorder. $J$ Psychiatr Pract 2013;19:42-53.

17 Sheehan DV, Lecrubier Y, Harnett Sheehan K, et al. The validity of the mini international neuropsychiatric interview (mini) according to the SCID-P and its reliability. European Psychiatry 1997;12:232-41.

18 Goodman WK, Price LH, Rasmussen SA, et al. The Yale-Brown obsessive compulsive scale. I. development, use, and reliability. Arch Gen Psychiatry 1989;46:1006-11.
19 Ritsher JB, Otilingam PG, Grajales M. Internalized stigma of mental illness: psychometric properties of a new measure. Psychiatry Res 2003;121:31-49.

20 Singh A, Grover S, Mattoo SK. Validation of Hindi version of internalized stigma of mental illness scale. Indian J Soc Psychiatry 2016;32:104-14.

21 Thompson K, Kulkarni J, Sergejew AA. Reliability and validity of a new medication adherence rating scale (MARs) for the psychoses. Schizophr Res 2000;42:241-7.

22 Verma P, Mahour P, Dalal PK, et al. Severity and dimensions of obsessive-compulsive disorder and family accommodation: OCD severity and family accommodation. Indian Journal of Mental Health 2019;6:56-61.

23 Jaisoorya TS, Janardhan Reddy YC, Nair BS, et al. Prevalence and correlates of obsessive-compulsive disorder and subthreshold obsessive-compulsive disorder among college students in Kerala, India. Indian J Psychiatry 2017;59:56-62.

24 Subramaniam M, Abdin E, Vaingankar JA, et al. Obsessivecompulsive disorder: prevalence, correlates, help-seeking and quality of life in a multiracial Asian population. Soc Psychiatry Psychiatr Epidemiol 2012;47:2035-43.

25 Deepthi K, Kommu JVS, Smitha M, et al. Clinical profile and outcome in a large sample of children and adolescents with obsessivecompulsive disorder: a chart review from a tertiary care center in India. Indian J Psychaitry 2018;60:205-12.

26 Latalova K, Prasko J, Kamaradova D, et al. Self-stigma and suicidality in patients with neurotic spectrum disorder - a cross sectional study. Neuro Endocrinol Lett 2014;35:474-80.

27 Ociskova M, Prasko J, Kamaradova D, et al. Relationship between internalized stigma and treatment efficacy in mixed neurotic spectrum and depressive disorders. Neuro Endocrinol Lett 2014;35:101-7.

28 Holubova M, Prasko J, Ociskova M, et al. Quality of life, selfstigma, and coping strategies in patients with neurotic spectrum disorders: a cross-sectional study. Psychol Res Behav Manag 2019;12:81-95.

29 Hajda M, Kamaradova D, Prasko J. Self-stigma, treatment adherence and medication discontinuation in patients with bipolar disorders in remission: a cross-sectional study. Act Nerv Super Redviva 2015:57:6-11.

30 Adewuya AO, Owoeye OA, Erinfolami AR, et al. Prevalence and correlates of poor medication adherence amongst psychiatric outpatients in southwestern Nigeria. Gen Hosp Psychiatry 2009;31:167-74.

31 Kamaradova D, Cinculova A, Prasko J, et al. Adherence, selfstigma and discontinuation of pharmacotherapy in patients with anxiety disorders: cross-sectional study. European Psychiatry 2015;30:1116.

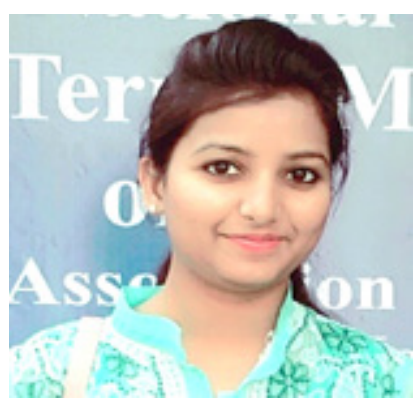

Eram Ansari is a M.Sc Psychiatric Nursing student at KGMU College of Nursing, King George's Medical University, Lucknow, Uttar Pradesh, India. She is a registered nurse and completed a B.Sc Nursing at the College of Nursing, Sanjay Gandhi Post Graduate Institute of Medical Sciences (SGPGIMS), Lucknow, India. She has attended various national conferences and workshops. She has a keen interest in research and teaching. Her research interests include anxiety disorders, social psychiatry, forensic psychiatry and suicide prevention. 